\title{
Behavioral effects of MK-801 mimic deficits associated with hippocampal damage
}

\author{
GEORGE S. ROBINSON, JR., GEOFFREY B. CROOKS, JR., \\ PAUL G. SHINKMAN, and MICHELA GALLAGHER \\ University of North Carolina, Chapel Hill, North Carolina
}

\begin{abstract}
This study was undertaken to assess the behavioral effects of MK-801 [(+)-5-methyl-10,11-dihydro5H-dibenzo-[a,d]cyclo-hepten-5,10-imine maleate], an anticonvulsant that binds to PCP sites and thereby blocks N-methyl-D-aspartate (NMDA) function. Such compounds prevent long-term potentiation (LTP) in the hippocampus and provide an important tool for assessing whether animals depend on LTP for learning. The results of the present experiments indicate that MK-801 administration impairs acquisition of some forms of learning (i.e., spatial learning and taste potentiation of an acquired odor aversion) that are normally dependent on the integrity of the hippocampal formation. In a narrow dose range, deficits were obtained on these tasks while other measures of learning/performance (i.e., cue learning in the same maze as was used for assessment of spatial learning, and simple associations formed between either a taste or odor stimulus paired with an effective unconditioned stimulus) were spared. These results are consistent with the view that an NMDA mechanism is critical for certain forms of learning, and that the effects of MK-801 mimic deficits produced by hippocampal damage.
\end{abstract}

Recent interest has focused on the role of $\mathrm{N}$-methyl-Daspartate (NMDA) receptors in learning (for a review, see Cotman, Monaghan, \& Ganong, 1988). The highest concentrations of NMDA binding sites in the brain are found in area CA1 of the hippocampus, with substantial concentrations also localized within the dentate gyrus (Monaghan \& Cotman, 1986; Monaghan, Holets, Toy, $\&$ Cotman, 1983). These receptors are involved in a form of synaptic plasticity known as long-term potentiation (LTP), a long-lasting increase in synaptic efficacy induced by brief, high-frequency afferent stimulation. The development of compounds that are highly selective antagonists at NMDA receptors has led to the observation that these drugs block LTP, but not normal fast excitatory transmission, in the CA1 region of the hippocampus and at perforant path/granule cell synapses in the dentate gyrus (Bliss \& Lomo, 1973; Collingridge, Kehl, \& McClennan, 1983; Errington, Lynch, \& Bliss, 1987; Harris, Ganong, \& Cotman, 1984; Morris, Anderson, Lynch, \& Baudry, 1986). A class of compounds that bind noncompetitively to phencyclidine (PCP) sites also blocks NMDA function, presumably by regulation of the NMDA receptor/ionophore complex (Anis, Berry, Burton, \& Lodge, 1983; Coan \& Collingridge, 1987). These agents, like NMDA antagonists, impair the induction of LTP (Stringer \& Guyenet, 1983).

An attractive current hypothesis is that LTP provides a mechanism for storing information in the mammalian

This research was supported by NIMH Grant MH35554 and a Research Career Development Award (NIMH KO2-MH00406) to Michela Gallagher. Send correspondence to George S. Robinson, Jr., Department of Psychology, CB 3270, Davie Hall, University of North Carolina, Chapel Hill, NC 27599. brain. Attempts to assess whether intact animals use LTP to execute an information-storage function are few (Berger, 1984; Green \& Greenough, 1986; Sharp, McNaughton, \& Barnes, 1985). Pharmacological agents that interfere with the induction of LTP provide important tools for this analysis. If LTP is a critical mechanism for memory, then animals treated with NMDA antagonists should have pronounced behavioral deficits on learning/memory tasks. At the same time, such studies may reveal that the effects of interfering with NMDA function will depend on the type of task. For example, Morris et al. (1986) reported that intraventricular administration of the NMDA antagonist D-AP5 (D-2-amino-5-phosphonopentanoic acid), at a dose that blocked LTP in the perforant path, impaired the spatial learning ability of rats in a water maze. This form of learning is highly dependent on the integrity of the hippocampal formation (Morris, Garrard, Rawlins, \& O'Keefe, 1982). Intraventricular D-AP5 administration, however, did not alter the performance of rats on acquisition of a visual discrimination task (Morris et al., 1986).

The present investigation was undertaken to assess the behavioral effects on MK-801 [(+)-5-methyl-10,11dihydro-5H-dibenzo[a,d]cyclo-hepten-5,10-imine maleate], an anticonvulsant that binds to PCP sites, on learning. Unlike NMDA antagonists, MK-801 readily crosses the blood-brain barrier and can be administered systemically. In an initial series of experiments, we examined the effects of MK-801 on performance in the Morris water maze. These experiments were designed to assess whether MK-801 mimics the impairments produced by either hippocampal damage or NMDA antagonist administration on this spatial learning task. After these experiments, we assessed the effects of MK-801 on the acquisition of tastepotentiated odor aversion, another form of learning that 
is sensitive to hippocampal damage in the rat (BermudezRattoni, Coburn, Fernandez, Chavez, \& Garcia, 1987; Miller, Nonneman, Kelly, Neisewander, \& Isaac, 1986).

\section{EXPERIMENT 1}

In this experiment, we examined the effects of MK-801 on performance in the Morris water maze. In addition to making an assessment of spatial learning, we examined the general sensorimotor effects of MK-801 in the same apparatus, by analyzing the performance of animals on a habituation trial and during cue training, in a task that involved escape to a visible platform.

\section{Method}

Subjects. Forty experimentally naive male Long-Evans rats obtained from the Charles River Breeding Laboratories (Raleigh, NC) served as subjects. The animals were housed in individual cages with free access to food and water. The vivarium was maintained at $25^{\circ} \mathrm{C}$ on a $12: 12$-h light:dark cycle (lights on at 7 a.m.). Experiments were conducted between 10:00 a.m. and 1:00 p.m. The rats weighed $300-350 \mathrm{~g}$ at the time of behavioral testing.

Apparatus. The testing apparatus consisted of a circular galvanized steel tank $($ depth $=.58 \mathrm{~m}$, diameter $=1.83 \mathrm{~m}$ ), which served as a water maze. The interior surface of the maze was painted white. The maze was filled to a depth of $35.5 \mathrm{~cm}$ with lukewarm water $\left(27^{\circ} \mathrm{C}\right)$, which was made cloudy by the addition of $0.9 \mathrm{~kg}$ of powdered milk. During "place" training, a camouflaged white escape platform (height $=34.5 \mathrm{~cm}$, diameter $=10.2 \mathrm{~cm}$ ) was submerged $1 \mathrm{~cm}$ below the water's surface in the center of one quadrant of the maze. A black platform of identical construction, but measuring $37.0 \mathrm{~cm}$ in height, was used for "cue" training: this platform was visible approximately $1.0 \mathrm{~cm}$ above the water surface. Black patterns were affixed to white muslin curtains that surrounded the maze. These patterns provided an arrangement of spatial cues. A Panasonic WV-241 video camera (wide-angle lens) was placed above the center of the water maze. Data were collected and analyzed by a video tracking system (HVS Image Analyzer VP-112 and IBM PC-compatible computer), with software developed by San Diego Instruments, Inc. An Andex Color-I monitor situated outside the curtained area was used by the experimenter to locate the animal's position in the maze.

Procedure. All animals were handled ( $3 \mathrm{~min} /$ day) for 7 days before the start of the experiment. Behavioral testing occurred on 5 consecutive days. On Day 1, each animal was habituated to the water maze. On this habituation trial, each animal was placed in the maze for $90 \mathrm{sec}$ without an escape platform present, and then returned to its home cage. The animals received place training for the next 3 consecutive days (six trials/day). During each session, the submerged/camouflaged escape platform was positioned in the maze and remained in the same location throughout place training. The animal's starting position, however, varied. The animals were introduced into the maze at one of four equally spaced locations around the perimeter of the tank, with the provision that every four trials included varying permutations of the four starting locations. This procedure precluded the effective use of a response strategy for locating the escape platform (e.g., always turning left from the starting location). On each trial, the animal was placed, facing the wall, into the water and given $90 \mathrm{sec}$ to find the escape platform. If the animal failed to locate the platform within $90 \mathrm{sec}$, the experimenter placed the animal on the platform. The animal remained on the platform for $30 \mathrm{sec}$, prior to placement in a holding cage for a 60 -sec intertrial interval. At the completion of the session, the animal was returned to its home cage.

The last day of testing (Day 5) consisted of a free swim, followed by cue training. For the free swim, each animal was placed in the maze for $60 \mathrm{sec}$ with the escape platform removed. Analysis of the animal's search pattern on this trial provided a measure of spatial bias-that is, the percentage of pathlength traversed in the quadrant of the maze that formerly contained the escape platform versus the percentage of pathlength in the quadrant $180^{\circ}$ from the training quadrant. Immediately after the free swim, the animals received six cue-training trials. During cue training, the animals were permitted to escape to the visible platform, which was positioned in different locations from trial to trial. The animals were allotted $60 \mathrm{sec}$ to locate the platform on these trials.

The animals were randomly assigned to one of four groups ( $n=10$ for each group): a vehicle-injected control group, and groups that received $0.01,0.05$, or $0.08 \mathrm{mg} / \mathrm{kg}$ of $\mathrm{MK}-801$ in a $0.5 \mathrm{ml} / \mathrm{kg}$ volume of physiological saline. All animals received a subcutaneous injection 20 min prior to each session of behavioral testing (Days 1-5)

\section{Results}

Habituation: Day 1. Performance on the habituation trial provided an estimate of proficiency and speed of swimming under the drug treatment. This trial was analyzed to assess the total distance traversed in the maze during the $90-\mathrm{sec}$ interval. These data suggested that animals receiving the high dose $(0.08 \mathrm{mg} / \mathrm{kg})$ traversed a shorter distance than did the other groups. Pathlengths (mean $\pm S E M$ ) for the vehicle group and the groups injected with ascending doses of MK-801 were $28.9 \pm 1.6$, $25.7 \pm 2.2,28.2 \pm 3.2$, and $20.0 \pm 2.7 \mathrm{~m}$, respectively. An analysis of variance performed on these data, however, did not reveal a significant main effect for dose $[F(3,36)=$ $2.58, p<.07]$. The animals in the high-dose group nonetheless often exhibited an unusual pattern of swimming during the habituation trial: unlike the animals in the other groups, some of these subjects circled or turned abruptly in a confined region of the maze (see Figure 1), indicating that upon first exposure to the maze, their exploration was not entirely normal. The swimming patterns of animals in the 0.05 - and $0.01-\mathrm{mg} / \mathrm{kg}$ groups were indistinguishable from those in the control group.

Latencies on training trials: Days 2-4. Administration of MK-801 produced a significant impairment in place
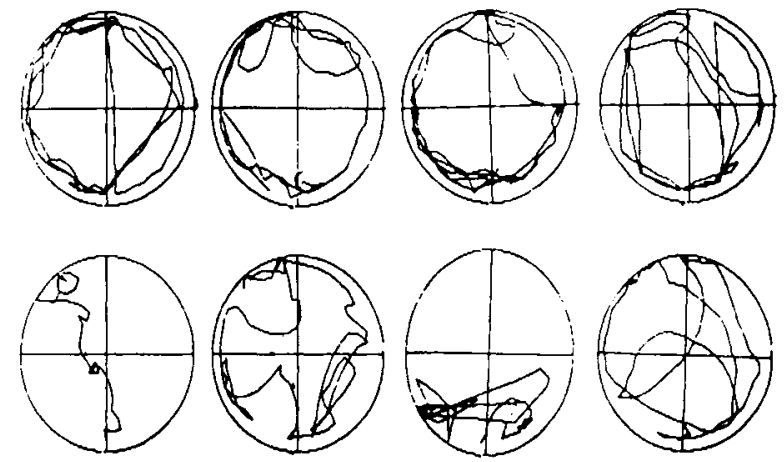

Figure 1. Representative swimming patterns of the vehicle-injected animals (above) and $0.08-\mathrm{mg} / \mathrm{kg}$ injected animals (below) on the habituation trial. Notice that the control animals typically remained in close proximity to the wall as they explored the maze, while most of the drug-injected animals deviated from this pattern. Some of the animals in the $0.08-\mathrm{mg} / \mathrm{kg}$ group traveled in a more restricted region of the maze. 


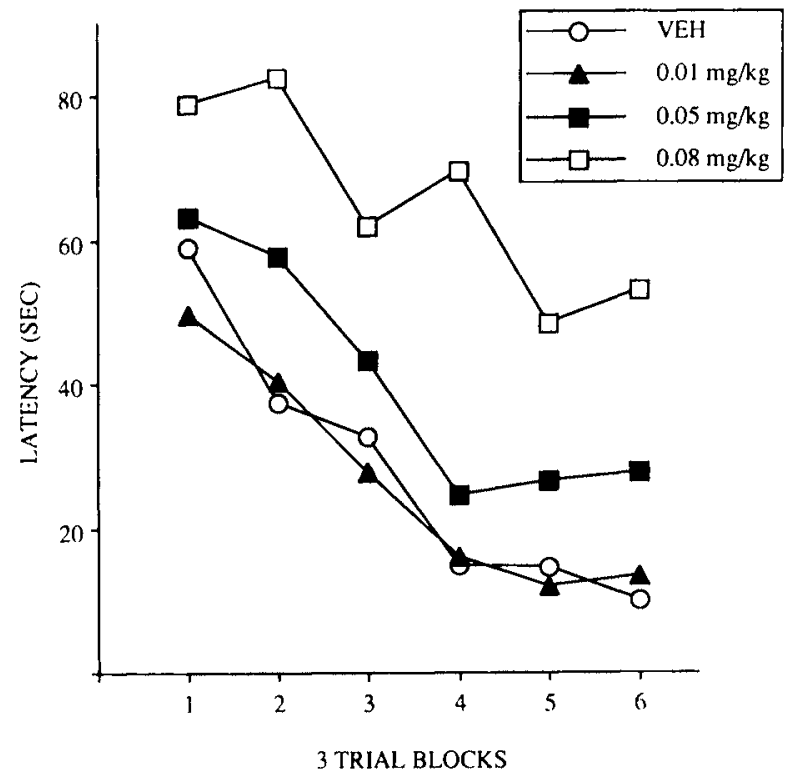

Figure 2. Mean latencies to locate the escape platform across six blocks of three training trials each.

learning, as indicated by latencies to locate the platform on the training trials (see Figure 2). A two-way analysis of variance performed on these data revealed significant main effects for dose $[F(3,36)=22.25, p<.0001]$ and for blocks of training trials $[F(5,180)=41.75, p<.0001]$. The interaction term (dose $\times$ trial block) was not significant. Comparisons among the groups (Neuman-Keuls) showed that the 0.05 - and $0.08-\mathrm{mg} / \mathrm{kg}$ groups each differed significantly from the control group. For the $0.08-\mathrm{mg} / \mathrm{kg}$ group, this difference was evident on each block of trials throughout training. For the $0.05-\mathrm{mg} / \mathrm{kg}$ group, this difference emerged by the second block and was significant on each block thereafter.

Pathlength on training trials: Day 4. Administration of MK-801 also increased the distance traversed to locate the escape platform. Statistical analysis of the pathlength data for the final training session revealed significant effects of dose $[F(3,36)=12.63, p<.0001]$ and trials $[F(5,180)=4.70, p<.0005]$. There was no significant interaction. Comparisons among the groups (NeumanKeuls) showed that the high- and intermediate-dose groups each differed significantly from the control group ( $p s<.01$ ). No reliable difference was found in comparison of the $0.01-\mathrm{mg} / \mathrm{kg}$ group with the vehicle control group.

Free swim: Day 5. As is shown in Figure 3, the animals in the control group had an appropriate spatial bias during the free swim: a greater proportion of the pathlength was traversed in the quadrant of the maze that formerly contained the escape platform than would be expected by chance (i.e., 25\%). This search pattern contrasts with that observed in the drug-injected groups. Analysis of the data shown in Figure 3 revealed significant main effects for dose $[F(1,36)=3.71, p<.02]$ and quadrant
$[F(1,36)=10.34, p<.003]$. There was also a significant dose $\times$ quadrant interaction $[F(3,36)=3.94$, $p<.02]$. Analysis of the interaction for simple effects $(F$ tests) indicated significant group differences for percentage of pathlength in the training quadrant and in the opposite quadrant $(p<.05)$ : MK-801 dose-dependently decreased searching in the training quadrant and increased the percentage of pathlength in the opposite quadrant. In addition, only the control group and the $0.01-\mathrm{mg} / \mathrm{kg}$ group had a reliable spatial bias, as was indicated by a significant difference in the percentage of pathlength between the quadrants for each of these groups $(p<.01)$. No significant spatial bias, however, was found for the 0.05and $0.08-\mathrm{mg} / \mathrm{kg}$ groups.

Cue training: Day 5. Latencies to locate the visible platform during cue training are shown in Figure 4. There was a significant difference among the groups $[F(3,36)=$ $10.25, p<.0001]$. Post hoc comparisons among groups (Neuman-Keuls) revealed that the $0.08-\mathrm{mg} / \mathrm{kg}$ group differed from the control group $(p<.01)$. The 0.01 - and $0.05-\mathrm{mg} / \mathrm{kg}$ groups did not, however, differ significantly from the vehicle control group.

\section{Discussion}

The results of this experiment indicate that administration of MK-801 impairs performance in the Morris water maze. At the high dose $(0.08 \mathrm{mg} / \mathrm{kg})$, the drug produced a deficit that was evident during both place and cue training. At this dose, a noticeable difference in the pattern of swimming was also observed on the habituation trial. In contrast, following administration of the intermediate

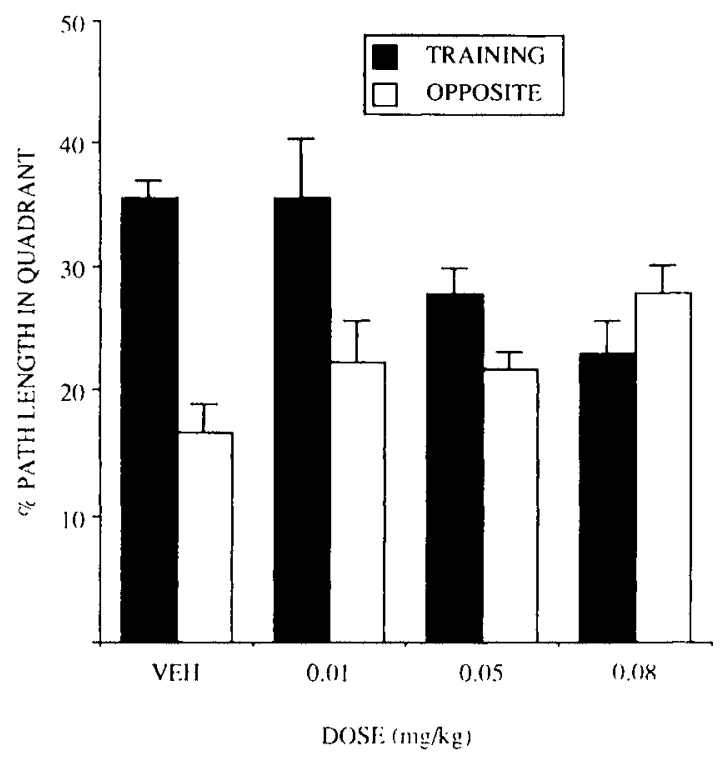

Figure 3. Mean (+SEM) percentage of the total pathlength that was traversed in the training and opposite quadrants during the free swim. Training $=$ maze quadrant where the escape platform was located during training. Opposite $=$ quadrant located $180^{\circ}$ from the training quadrant. Only the vehicle-injected and $0.01-\mathrm{mg} / \mathrm{kg}$ groups had a significant spatial bias for the training quadrant. See text for description of the statistical results. 


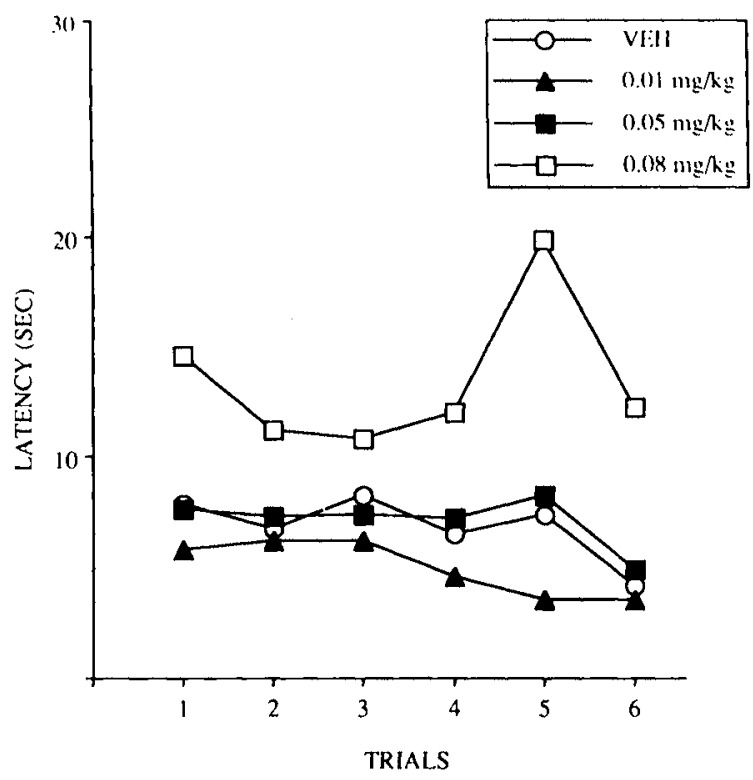

Figure 4. Mean escape latencies across trials during cue training.

dose $(0.05 \mathrm{mg} / \mathrm{kg})$, a deficit in place learning was observed without disruption of performance during either the habituation trial or cue training. At this dose, the animals had longer latencies and pathlengths during the place-training trials. During the free swim, the animals treated with $0.05 \mathrm{mg} / \mathrm{kg}$ of MK-801 failed to exhibit a significant spatial bias for the training quadrant. Nonetheless, these animals escaped proficiently during the cuetraining trials that immediately followed the free swim. Although a steep dose-response effect was observed, the behavioral data suggest that, within a narrow dose range, MK-801 produces a place-learning impairment that is not confounded by a sensorimotor performance deficit. This pattern of results resembles the effects of hippocampal damage that impairs place learning, in animals that perform the cue version of the task normally (Morris et al., 1982).

\section{EXPERIMENT 2}

The purpose of this experiment was to further assess the extent to which the behavioral effects of MK-801 in the water maze reflect performance deficits as distinct from a learning impairment. This was done with different regimens of drug administration. Groups that had received prior training on the spatial task in a vehicle condition were tested on the free swim following drug administration. Groups were also included to determine whether animals trained under the drug were impaired when the vehicle was administered prior to the free swim trial.

\section{Method}

Subjects. Thirty-three experimentally naive Long-Evans adult male rats served as subjects. The animals were maintained as was described for Experiment 1.
Procedure. The testing apparatus and place-training procedures were identical to those described for Experiment 1. Four groups of animals were included in this experiment: a vehicle-injected control group $(n=8)$; a group that received $0.08 \mathrm{mg} / \mathrm{kg}(n=9)$ prior to each session except the final free swim trial; and groups that received the drug ( 0.05 or $0.08 \mathrm{mg} / \mathrm{kg}, n=8$, for each group) only prior to the free swim. The drug-injected groups received vehicle injections prior to the sessions for which drug treatments were omitted. All animals received injections $20 \mathrm{~min}$ prior to behavioral testing.

\section{Results}

A two-way analysis of variance (group $\times$ quadrant) was conducted on the free swim data (Figure 5). There was a significant main effect for quadrant $[F(1,29)=22.35$, $p<.0001]$, as well as a significant group $\times$ quadrant interaction $[F(3,29)=2.29, p<.034]$. The main effect for group was not significant. Further analysis of the interaction for simple effects revealed that the group trained under MK-801 $(0.08 \mathrm{mg} / \mathrm{kg})$ but tested without the drug failed to show a significant spatial bias on the free swim. In contrast, groups that were trained in the vehicle condition and only then tested under the drug $(0.05$ or $0.08 \mathrm{mg} / \mathrm{kg})$ each had a prominent spatial bias $(p<.005)$ that did not differ significantly from that for the vehicle control group.

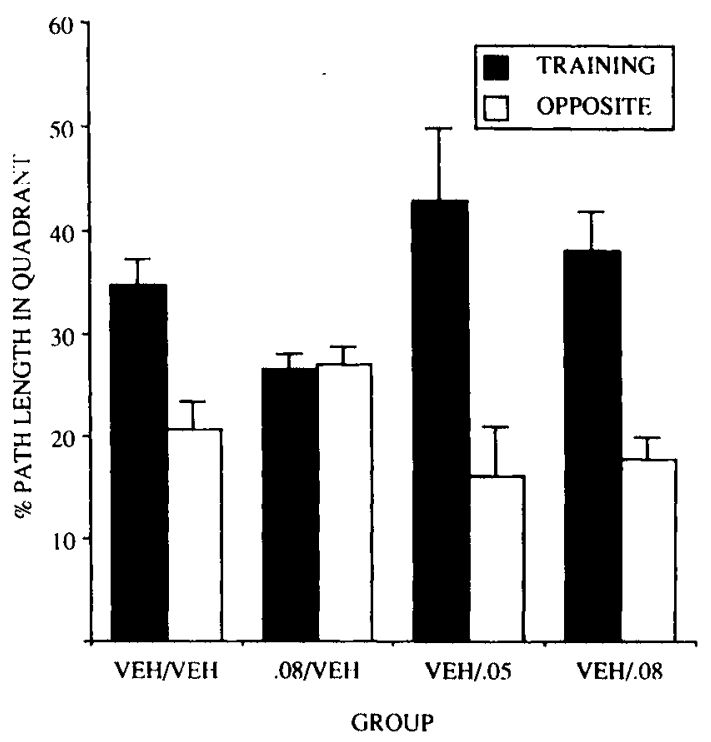

Figure 5. Mean ( + SEM) percentage of the total pathlength that was traversed in the training and opposite quadrants during the free swim for groups in Experiment 2. VEH/VEH = Group trained following injection of vehicle and tested under vehicle. .08/VEH $=$ Group trained following injection of 0.08-mg/kg MK-801 but tested under vehicle. VEH/.05 = Group trained following vehicle injection but tested under 0.05 -mg/kg MK-801. VEH/.08 = Group trained following vehicle injection but tested under a $0.08-\mathrm{mg} / \mathrm{kg}$ dose of the drug. The VEH/.05 and VEH/.08 groups each had a significant spatial bias that did not differ from that for the VEH/VEH group. In contrast, the .08/VEH did not have a significant spatial bias for the training quadrant. The results of the statistical analyses are reported in the text. 


\section{Discussion}

These results indicate that administration of MK-801 does not disrupt performance of place learning in animals that acquired the task prior to drug treatment. Thus even the high dose $(0.08 \mathrm{mg} / \mathrm{kg})$ was not sufficient to disrupt performance on the free swim when animals were trained under the vehicle condition. This contrasts with the results for animals trained under $0.08 \mathrm{mg} / \mathrm{kg}$ of MK-801 but tested for spatial bias under the vehicle condition: these animals did not show any evidence of spatial learning on the free swim trial.

\section{EXPERIMENT 3}

Interference with NMDA function impairs the induction, but not the maintenance, of LTP (see Bliss \& Lynch, 1988 , for a recent review). If the effects of MK-801 on place learning reflect interference with an LTP mechanism, then it would be predicted that pretraining administration would be required to impair performance. This expectation is consistent with the results of Experiment 2, in which the performance of animals that had already learned the task was not disrupted by MK-801. In Experiment 3 , we examined the effects of immediate posttraining MK-801 administration on the retention of place learning.

\section{Method}

Subjects. Twenty-four experimentally naive Long-Evans male rats served as subjects. They were maintained as was described for Experiment 1.

Procedure. The place-training procedures were identical to those described for Experiment 1. The animals were assigned to one of three groups. A control group $(n=8)$ received posttraining saline injections. The two remaining groups received either 0.1 or $0.5 \mathrm{mg} / \mathrm{kg}$ of MK -801 ( $n=8$, for each group). The $0.1-\mathrm{mg} / \mathrm{kg}$ dose approximates the high dose used in Experiment 1 . An even higher dose was used in Experiment 3 as well $(0.5 \mathrm{mg} / \mathrm{kg})$, because the animals were not required to perform under drug treatment. All animals received injections immediately following the last trial of each place training session.

\section{Results}

Posttraining administration of MK-801 did not interfere with retention when the drug was given immediately after each training session (Figure 6). An analysis of variance performed on the data from the free swim revealed no significant effects for group or for the group $\times$ quadrant interaction. There was an overall significant effect for quadrant $[F(1,23)=38.50, p<.0001]$, indicating that, irrespective of drug treatment, each group exhibited a spatial bias during the free swim. These results for the final free swim are consistent with the absence of any effect of drug treatment on latencies to locate the escape platform during the training phase (data not shown).

\section{Discussion}

The results of this experiment are consistent with earlier findings on NMDA function and LTP in the hippocampus: NMDA antagonists impair the induction, but not the main-

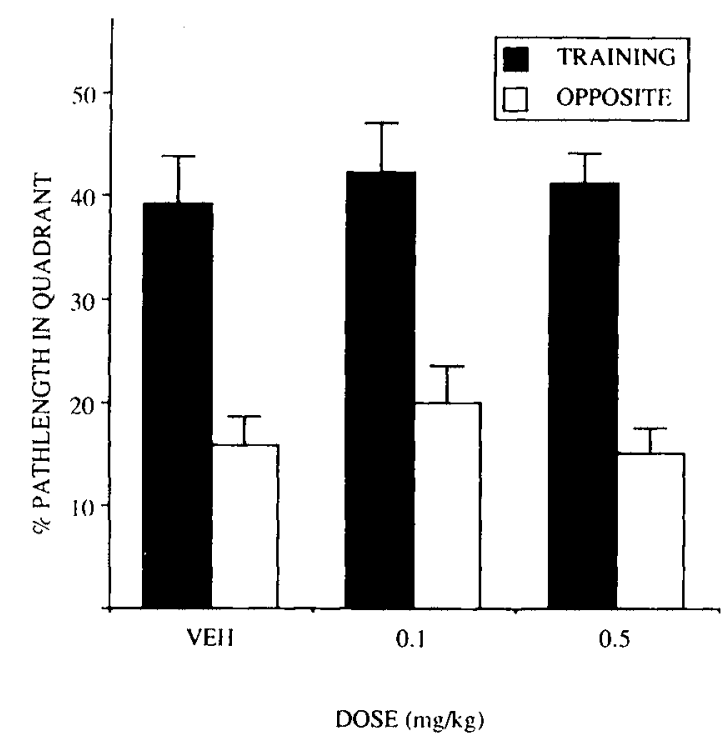

Figure 6. Mean ( $+S E M)$ percentage of total pathlength traveled in the training and opposite quadrants on the free swim for groups in Experiment 3. Training = maze quadrant where the escape platform was located during training. Opposite $=$ quadrant located $180^{\circ}$ from the training quadrant. All groups exhibited a comparable spatial bias.

tenance of LTP. In the next experiment, we extended our examination of MK-801 to another learning task, taste potentiation of an odor aversion. The common element in this task and the spatial learning task was sensitivity to hippocampal damage.

\section{EXPERIMENT 4}

The rodent hippocampal formation receives inputs from the olfactory system, a sensory modality that extensively innervates the entorhinal cortex (Krettek \& Price, 1977). Recent studies have explored the contribution of hippocampal processing to some forms of olfactory learning. Among these, several studies have reported that hippocampal damage and intrahippocampal pharmacological treatments impair taste potentiation of odor-aversion learning (T/O potentiation) (Bermudez-Rattoni et al., 1987; Miller, Nonneman, et al., 1986). In this task, animals acquire a pronounced aversion to an odor that is followed by illness, only if the odor is presented together with a gustatory stimulus during training (Holder \& Garcia, 1987; Rusiniak, Hankins, Garcia, \& Brett, 1979). Typically, T/O potentiation experiments are conducted with separate groups of animals that are trained under one of three conditions: either taste or odor alone is paired with illness, or a taste/odor compound is paired with illness. Following training, the animals are tested with each component of the compound (taste or odor alone) on separate occasions. Taste potentiation of odor aversion refers to the observation that animals trained with the compound stimulus acquire a strong aversion to the odor, whereas animals trained with the odor alone do not. Using this task, 
we assessed the effects of MK-801 at a $0.05-\mathrm{mg} / \mathrm{kg}$ dose. Pilot work for this study indicated that a $0.1-\mathrm{mg} / \mathrm{kg}$ dose of MK-801 induced some suppression of drinking in waterdeprived rats, but a $0.05-\mathrm{mg} / \mathrm{kg}$ dose was without effect on baseline drinking.

\section{Method \\ Subjects. Forty-six experimentally naive male Long-Evans rats served as subjects. The animals were housed and maintained as was described for Experiment 1.}

Apparatus. Four Coulbourn animal test chambers $(11 \times 10 \times 12$ in.) positioned in sound-attenuated cubicles with exhaust fans were used in this experiment. A drinking tube (from a $100-\mathrm{ml}$ bottle) with optical lickometer was positioned at one end of the test chamber. The data were recorded on an Apple II+ computer with a Coulbourn Instruments LabLinc interface.

Procedure. Prior to Experiment 4, the animals were adapted to a drinking schedule in which water was available for $5 \mathrm{~min}$ in the morning (9:00 a.m.) and again for $15 \mathrm{~min}$ in the afternoon (4:30 p.m.). During this adaptation phase, the animals were handled daily. After 5 days of adaptation, the animals were placed in the test chambers for $5 \mathrm{~min}$ each day, and the amount of water consumed was monitored until a stable baseline was achieved ( 5 days). Throughout this phase and the remainder of the experiment, the animals continued to receive a 15 -min presentation of water in the home cage in the afternoon (4:30 p.m.). A single training trial consisted of a 5-min drinking session in the test chamber, followed $30 \mathrm{~min}$ later by administration of $\mathrm{LiCl}(190 \mathrm{mg} / \mathrm{kg}, 3.0 \mathrm{M})$. Prior to the training trial, the animals were randomly assigned to one of three training conditions. These included presentation of saccharin $(0.1 \%)$, presentation of water with an odor disk mounted at the drinking spout, or presentation of both saccharin and an odor disk at the spout. The odor disk consisted of a $1-\mathrm{cm}^{2}$ piece of filter paper with $30 \mu$ l of pure almond extract (McCormick). Half of the animals in each training condition received an injection of MK-801 $(0.05 \mathrm{mg} / \mathrm{kg}) 20 \mathrm{~min}$ prior to training. The remaining animals received an injection of the vehicle.

After training, the animals received 2 days of water presentation ( $5 \mathrm{~min}$ ) in the test apparatus each morning, in order to reestablish baseline drinking. To assess the learned aversions to the taste and odor, either the taste or the odor was presented alone, on separate occasions. All animals received one presentation of each stimulus with 2 intervening days of water-only presentation. The order of testing was the same for all animals, beginning with an odor test. This was done to ensure that robust $T / O$ potentiation would be obtained in the control animals that were trained with the taste/odor compound. There is some evidence that the basis for $\mathrm{T} / \mathrm{O}$ potentiation depends on a within-compound association (Miller, McCoy, Kelly, \& Bardo, 1986). Thus presentation of one of these stimuli to animals that received compound training could promote some extinction to each component of the compound. Because T/O potentiation extinguishes rather rapidly, the test with the odor was conducted prior to the taste test. Suppression ratios were calculated for each test, with the preceding day's water consumption as the baseline. The ratio was $A / A+B$, where $A=$ consumption in the test session and $\mathrm{B}=$ consumption in the baseline session. Thus a suppression ratio of .50 would reflect equivalent consumption in the baseline and test sessions.

\section{Results}

Suppression ratios for the training trial were computed, with the prior day's session as baseline. A one-way analysis of these data indicated a significant group effect $[F(5,40)=7.56, p<.001]$. Subsequent comparisons
(Neuman-Keuls) indicated that the animals exposed to the saccharin during training ( $\mathrm{T}-\mathrm{LiCl}$ and $\mathrm{T} / \mathrm{O}-\mathrm{LiCl}$ groups) differed from the animals exposed to the odor alone during training. In each training condition, however, there was no significant difference between vehicle- and MK-801-injected groups. The suppression ratios for the taste-exposed animals were on the average .29 , whereas for groups exposed to the odor they were .43 . These results indicate that saccharin provoked a greater neophobic response than did the olfactory stimulus. MK-801, however, did not alter neophobia or drinking under the drug treatment.

The suppression ratios for the taste and odor tests are shown in Figure 7. As shown in the left panel, all groups that were exposed to saccharin during training developed a taste aversion. Furthermore, comparable suppression of drinking during saccharin exposure was evident for animals trained with either the taste alone or the T/O compound, irrespective of drug treatment. As expected, the animals trained with the odor followed by $\mathrm{LiCl}$ did not exhibit a taste aversion. Statistical analysis supported this description: a one-way analysis of variance indicated a significant difference among the groups $[F(5,40)=56.49$, $p<.0001]$. Post hoc comparisons (Neuman-Keuls) revealed that the groups trained with either the saccharin alone or the $\mathrm{T} / \mathrm{O}$ compound had suppression ratios on the taste test that were significantly different from those for the groups in the odor-alone training condition $(p s<.01)$. The groups that were exposed to saccharin during training, however, did not differ from one another.

In the odor test, no aversion was evident for the groups trained with either the taste or the odor alone (see Figure 7 , right panel). Only the vehicle-injected control group that was trained with the T/O compound acquired a reliable odor aversion - that is, T/O potentiation. Acquisition of the odor aversion in the T/O training condition was markedly reduced by MK-801 administration. Statistical analysis revealed a significant difference among the groups for the odor test $[F(5,40)=16.94, p<.0001]$. Post hoc comparisons (Neuman-Keuls) revealed that the T/O vehicle-injected group differed from each of the other groups $(p<.01)$. The remaining groups, however, did not significantly differ from one another.

\section{Discussion}

The acquisition of an odor aversion that depended on the compound presentation of olfactory and gustatory stimuli was markedly impaired by the administration of MK-801. In contrast, drug treatment did not attenuate the acquisition of a taste aversion that was produced by pairing the gustatory stimulus with $\mathrm{LiCl}$. Due to the fact that delayed illness did not support the acquisition of an odor aversion when the animals were trained with the odor alone (Groups $\mathrm{O}-\mathrm{LiCl}$ ), the results of this experiment do not indicate whether the deficit in T/O potentiation produced by MK-801 is due to altered sensory/perceptual processing of the olfactory stimulus. The final experiment 

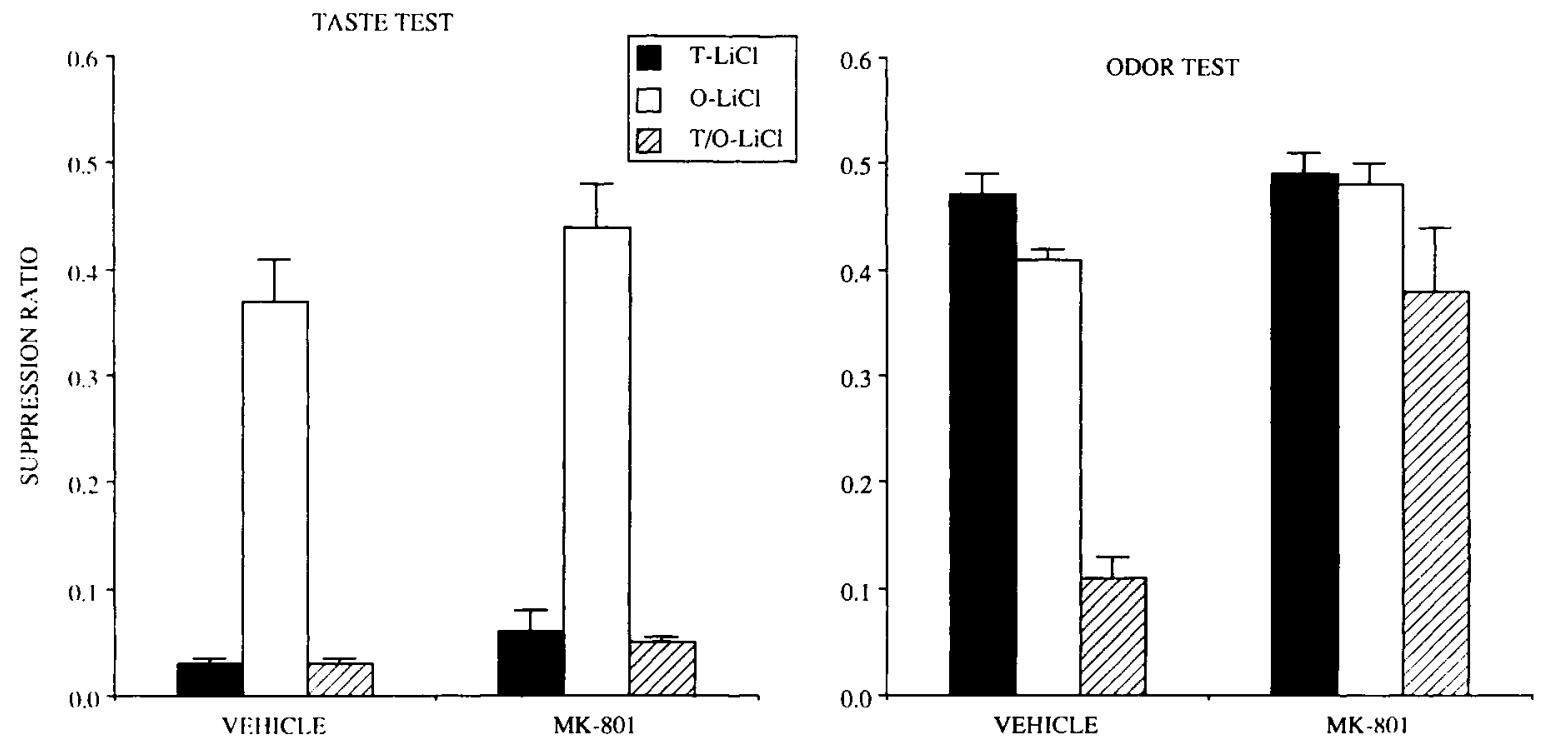

Figure 7. Suppression ratios (Mean +SEM) for groups in Experiment 4. Groups were trained by administration of LiCL $30 \mathrm{~min}$ after exposure to either saccharin $(\mathrm{T}-\mathrm{LiCl})$ or an odor cue $(\mathrm{O}-\mathrm{LiCl})$, or to the taste/odor compound $(\mathrm{T} / \mathrm{O}-\mathrm{LiCl})$. $\mathrm{Half}$ of the animals in each training condition received the vehicle and half received $\mathrm{MK}-801(0.05 \mathrm{mg} / \mathrm{kg}) \mathrm{prior}$ to training. The data in the left panel were obtained during a subsequent taste test, in which all groups were presented with saccharin. There was no effect of drug treatment: all animals exposed to saccharin during training ( $\mathrm{T}-\mathrm{LiCl}$ and $\mathrm{T} / \mathrm{O}-\mathrm{LiCl}$ ) developed a comparable taste aversion. The right panel illustrates the performance of the same animals during odor testing alone. MK-801 significantly impaired $T / O$ potentiation. See text for description of the statistical analysis.

was conducted to examine whether MK-801 would diminish sensory/perceptual processing for the olfactory cue that was used in the $\mathrm{T} / \mathrm{O}$ potentiation training condition.

\section{EXPERIMENT 5}

Experiment 5 was conducted in order to further assess whether a deficit in T/O potentiation produced by MK-801 could be attributed to impaired olfactory processing. In order to obtain a reliable measure of simple odor-aversion learning, the olfactory stimulus that was used in the previous experiment was paired with footshock. The effect of MK-801 $(0.05 \mathrm{mg} / \mathrm{kg})$ was assessed on this task.

\section{Method}

Subjects. Forty-four male Long-Evans rats served as subjects. The animals were housed and maintained as was described for Experiment 1.

Apparatus. The animal test chambers used in Experiment 4 were also used in Experiment 5. The grid floor of the chamber was connected to a shocker (Coulbourn Instruments) that was set to deliver a single footshock $(0.4 \mathrm{~mA}, 1.0 \mathrm{sec})$. An Apple II+ computer controlled shock delivery, which occurred at the end of a 1-min drinking session.

Procedure. The animals were initially adapted to a drinking schedule as described for the previous experiment. During adaptation to drinking in the animal test chambers, the duration of this session was reduced to $1 \mathrm{~min}$ and the animais received a 1-min morning session for 5 days to establish a stable baseline. On the training day, the animals were placed in the test chambers and allowed to drink for $1 \mathrm{~min}$. On this trial, an odor disk identical to that used in Experiment 4 was positioned at the water spout. For half the animals, this session terminated with the delivery of footshock $(0.4 \mathrm{~mA}, 1.0 \mathrm{sec})$. For the remainder, no shock was delivered. Half of the animals in each training condition received an injection of MK-801 $(0.05 \mathrm{mg} / \mathrm{kg}) 20 \mathrm{~min}$ prior to the training session, while the remainder received the vehicle.

Following training, the animals received 2 days of baseline recovery, each consisting of water-alone presentation for a 1-min session in the test chamber. On the test day, a 1-min drinking session was conducted with an odor disk positioned at the drinking spout. Suppression ratios were calculated using the preceding day's water consumption as baseline, as described for Experiment 4 .

\section{Results}

The suppression ratios for the four groups of animals in this experiment was shown in Figure 8. A one-way analysis of variance revealed a significant difference among the groups $[F(3,40)=3.48, p<.02]$. Planned orthogonal contrasts revealed that the no-footshock vehicleand drug-injected groups did not differ from one another. Each of these groups readily drank in the presence of the odor during the test. Compared to these control groups, the animals that received footshock paired with the odor significantly suppressed drinking when the odor was again presented during the test; this effect was comparable for both vehicle- and MK-801-injected groups $(p<.01$, compared with the control groups). Thus MK-801 administration does not appear to disrupt simple odoraversion learning at the same dose level that was found to impair taste potentiation of an odor aversion.

\section{GENERAL DISCUSSION}

The highest dose of MK-801 used in the initial watermaze studies $(0.08 \mathrm{mg} / \mathrm{kg})$ disrupted simple measures of 


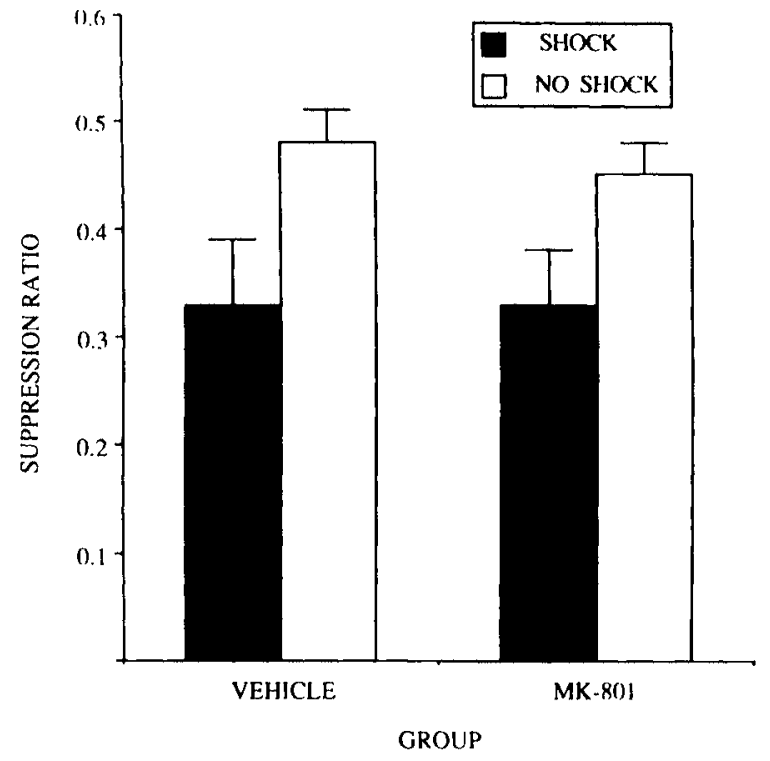

Figure 8. Suppression ratios (mean + SEM) for groups in Experiment 5. During training, animals were presented with an odor that was paired with footshock for some groups or no footshock for others. Groups in each of these training conditions were injected with either vehicle or MK-801 $(0.05 \mathrm{mg} / \mathrm{kg})$ prior to training. The data show performance in a test conducted 3 days after training in which the animals were again presented with the odor. Irrespective of drug treatment, the groups that received footshock in the presence of the odor subsequently suppressed drinking upon reexposure to the odor, as compared to the no-footshock control groups. Statistical analysis is described in the text.

performance. A lower dose of the drug produced a more selective impairment: a spatial learning deficit was obtained at $0.05 \mathrm{mg} / \mathrm{kg}$, without alteration of swimming proficiency or cue learning. When this dose was examined in Experiments 4 and 5, T/O potentiation was impaired without disruption of learning when either element of the T/O compound was paired, by itself, with an effective unconditioned stimulus. Thus, administration of MK-801, within a narrow dose range, appears to selectively disrupt certain forms of learning.

The steep dose-response function found in our work with MK-801 has implications for the use of this compound in behavioral research. A number of researchers have recently described impaired learning or memory with doses of MK-801 at $0.1 \mathrm{mg} / \mathrm{kg}$ and higher (Benvenga \& Spaulding, 1988; Tang \& Ho, 1988). In these studies, however, the possibility of performance impairments has not entirely been discounted, because direct estimates of such effects have not typically been provided. The performance deficit seen at the $0.08-\mathrm{mg} / \mathrm{kg}$ dose level in our work is consistent with other evidence that relatively low doses of MK-801 and PCP produce generalized changes in sensorimotor function, such as hyperlocomotion, repetitive sniffing, swaying, and a loss of equilibrium (Benvenga \& Spaulding, 1988; unpublished observations, Gallagher, September 1988; Koek, Woods, \& Winger, 1988), as well as performance changes that could indicate motivational impairments (Danyes, Wroblewski, \& Costa, 1988). Our pilot work for Experiment 4 (see above) indicated that consummatory behavior was adversely affected by a 0.1 $\mathrm{mg} / \mathrm{kg}$ dose. Thus, it is important to emphasize that an uncritical approach to the use of MK-801 may lead to an overestimation of the range of tasks in which this drug disrupts learning capacities as distinct from producing mere performance impairments.

The impairment obtained with MK-801 in the water maze is comparable to that produced by the competitive NMDA antagonist D-AP5. In earlier work, intraventricular administration of D-AP5 was found to impair place learning at a dose level that did not alter visual discrimination learning in the same water-maze apparatus (Morris et al., 1986). Thus, two different classes of pharmacological agents, which share the property of interfering with NMDA function, produce comparable effects on spatial learning. Our evidence that MK-801 disrupts the acquisition of T/O potentiation suggests that D-AP5 may also be effective in this task.

Because interference with NMDA function blocks neural plasticity in the hippocampus, our results are consistent with a role for LTP in preserving information that is critical to performance on these tasks. Moreover, specific features of the behavioral effects of MK-801 in these experiments parallel the results obtained with NMDA antagonists on LTP. Specifically, MK-801 had no detrimental effect on performance of spatial learning when animals were previously trained in the absence of drug treatment (Experiment 2), or when the drug was administered after the completion of each training session (Experiment 3). These results are consistent with evidence that blockade of NMDA function does not impair the maintenance or expression of LTP, but only its induction. Thus, it might be predicted that behavioral deficits would be obtained only when MK-801 was administered prior to acquisition, an expectation that conforms to the results of the present study.

The deficits obtained with MK-801 on both spatial learning and $T / O$ potentiation are similar to those produced by hippocampal damage. Such similarities do not necessarily indicate that the hippocampus is the sole target for MK-801, however. Other systems play a role in the forms of learning that were sensitive to drug treatment. For example, spatial learning deficits have been reported in animals with cortical damage (Kolb, Sutherland, \& Whishaw, 1983; Whishaw \& Kolb, 1984), and NMDA receptors in the cortex could provide additional targets for the effects of MK-801 on place learning. Although damage to the taste cortex does not alter T/O potentiation (Kiefer, Rusiniak, \& Garcia, 1982), this form of learning is impaired by lesions of the basolateral nucleus of the amygdala (ABL) complex (BermudezRattoni, Grijalva, Kiefer, \& Garcia, 1986; BermudezRattoni, Rusiniak, \& Garcia, 1983). Interestingly, the distribution of NMDA sites in the rat brain using in vitro autoradiography indicates relatively high binding in the ABL amygdala (Monaghan et al., 1986), a site where in- 
duction of LTP has been recently demonstrated (Chapman \& Brown, 1988). Studies involving microinjections of competitive and noncompetitive NMDA antagonists into specific brain targets are needed to clarify the site(s) of action for these compounds. In addition, further studies of both competitive and noncompetitive NMDA antagonists within other learning paradigms will help to delineate the conditions under which NMDA mechanisms may play a role in learning. The working hypothesis that guided the present research - that tasks which depend on the integrity of limbic/cortical function would be sensitive to NMDA antagonists-may continue to provide a useful framework for future studies.

\section{REFERENCES}

Anis, N. A., Berry, S. C., Burton, N. R., Lodge, D. (1983). The dissociative anaesthetics, ketamine and phencyclidine, selectively reduce excitation of central mammalian neurones by $\mathrm{N}$-methyl-aspartate. British Journal of Pharmacology, 79, 565-575.

Benvenga, M. J., SPaulding, T. C. (1988). Amnesic effect of the novel anticonvulsant MK801. Pharmacology, Biochemistry \& Behavior, 30, 205-208.

BERGER, T. W. (1984). Long-term potentiation of hippocampal synaptic transmission affects rate of behavioral learning. Science, 224, 627.

Bermudez-Rattoni, F., Coburn, K. L., Fernandez, J., Chavez, A. F., \& GARCIA, J. (1987). Potentiation of odor by taste and odor aversions in rats are regulated by cholinergic activity of dorsal hippocampus. Pharmacology, Biochemistry \& Behavior, 26, 553-559.

Bermudez-Rattoni, F., Grijalva, C. V., Kiefer, S. W., \&arcia, J. (1986). Flavor-illness aversions: The role of the amygdala in the acquisition of taste-potentiated odor aversions. Physiology \& Behavior, 38, 503-508.

Bermudez-Rattoni, F., Rusiniak, K. W., \& Garcia, J. (1983). Flavor-illness aversions: Potentiation of odor by taste is disrupted by application of novocaine into the amygdala. Behavioral \& Neural Biology, 37, 61-75.

BLISS, T. V. P., \& Lomo, T. (1973). Long-term potentiation of synaptic transmission in the dentate area of the anaesthetized rabbit following stimulation of the perforant path. Joumal of Physiology, 232, 331-356.

BLISs, T. V. P., LYNCH, M. A. (1988). Long-term potentiation of synaptic transmission in the hippocampus: Properties and mechanisms. In P. W. Landfield \& S. A. Deadwyler (Eds.), Long-term potentiation: From biophysics to behavior (pp. 3-72). New York: Alan R. Liss.

Chapman, P. E., Brown, T. H. (1988). Long-term potentiation in amygdala brain slices. Society for Neuroscience Abstracts, 14, 566 .

COAN, E. J., \& Collungridge, G. L. (1987). Effects of phencyclidine, SKF 10047 and related psychotomimetic agents on N-methyl-Daspartate receptor mediated synaptic responses in rat hippocampal slices. British Journal of Pharmacology, 91, 547-556.

Collingridge, G. L., Kehl, G. L., \& MCClennan, H. (1983). Excitatory amino acids in synaptic transmission in the Schaffer collateralcommissural pathway of the rat hippocampus. Journal of Physiology, 334, 33-46.

Cotman, C. W., Monaghan, D. T., \& Ganong, A. H. (1988). Excitatory amino acid neurotransmission: NMDA receptors and HebbType synaptic plasticity. Annual Review of Neuroscience, 11, 61-80.

DANYes, W., Wroblewski, J. T., Costa, E. (1988). Learning impairment in rats by $\mathrm{N}$-methyl-D-aspartate receptor antagonists. Neuropharmacology, 27, 653-656.

ERrington, M. L., LyNCh, M. A., \& Bliss, T. V. P. (1987). Longterm potentiation in the dentate gyrus: Induction and increased gluta- mate release are blocked by $\mathrm{D}(-)$ amino phosphonovalerate. Neuroscience, 20, 279-284.

Green, E. J., \& Greenough, W. T. (1986). Altered synaptic transmission in dentate gyrus of rats reared in complex environments: Evidence from hippocampal slices maintained in vitro. Joumal of Neurophysiology, 55, 739-750.

Harris, E. W., Ganong, A. H., \& Cotman, C. W. (1984). Long-term potentiation in the hippocampus involves activation of $\mathrm{N}$-methyl-Daspartate receptors. Brain Research, 323, 132-137.

HolDER, M. D., GARCIA, J. (1987). Role of temporal order and odor intensity in taste-potentiated odor aversions. Behavioral Neuroscience, 101, 158-163.

Kiefer, S. W., Rusiniak, K. W., \& Garcia, J. (1982). Flavor-illness aversions: Potentiation of odor by taste in rats with gustatory neocortex ablations. Journal of Comparative \& Physiological Psychology, 96, 540-548.

Koek, W., Woods, J. H., \& WINGER, G. D. (1988). MK-801, a proposed noncompetitive antagonist of excitatory amino acid neurotransmission, produces phencyclidine-like behavioral effects in pigeons, rats and thesus monkeys. Journal of Pharmacology \& Experimental Therapeutics, 245, 969-974.

KolB, B., Sutherland, R. J., \& Whishaw, I. Q. (1983). A comparison of the contributions of frontal and parietal association cortex to spatial localization in rats. Behavioral Neuroscience, 97, 13-27.

Krettek, J. E., \& Price, J. L. (1977). Projections from the amygdaloid complex and adjacent olfactory structures to the entorhinal cortex and to the subiculum in the rat and cat. Journal of Comparative Neurology, 172, 723-752.

Miller, J. S., MCCoy, D. F., Kelly, K. S., \& Bardo, M. T. (1986). A within-event analysis of taste-potentiated odor and contextual aversions. Animal Learning \& Behavior, 14, 15-21.

Miller, J. S., Nonneman, A. J., Kelly, K. S., Neisewander, J. L., \& ISAAC, W. L. (1986). Disruption of neophobia, conditioned odor aversion and conditioned taste aversion in rats with hippocampal lesions. Behavioral \& Neural Biology, 45, 240-253.

Monaghan, D. T., \& Cotman, C. W. (1986). Distribution of NMDAsensitive $\mathrm{L}-{ }^{3} \mathrm{H}$-glutamate binding sites in rat brain as determined by quantitative autoradiography. Jourmal of Neuroscience, 5, 2909-2919.

Monaghan, D. T., Holets, V. R., Toy, D. W., Cotman, C. W. (1983). Anatomical distributions of four pharmacologically distinct ${ }^{3} \mathrm{H}$-L-glutamate binding sites. Nature, 306, 176-179.

Morris, R. G. M., Anderson, E., LyNCH, G. S., \& Baudry, M. (1986). Selective impairment of learning and blockade of long-term potentiation by an $\mathrm{N}$-methyl-D-aspartate receptor antagonist, AP5. Nature, 319, 774-776.

Morris, R. G. M., Garrard, P., Rawuins, J. N. P., \& O'Keefe, J. (1982). Place navigation impaired in rats with hippocampal lesions. Nature, 297, 681-683.

Rusiniak, K. W., Hankins, W. G., Garcia, J., \& BRett, L. P. (1979). Flavor-illness aversions: Potentiation of odor by taste in rats. $\mathrm{Be}$ havioral \& Neural Biology, 25, 1-17.

Sharp, P. E., McNaughton, B. L., \& Barnes, C. A. (1985). Enhancement of hippocampal field potentials in rats exposed to a novel complex environment. Brain Research, 339, 361-365.

Stringer, J. L., \& GUYENET, P. G. (1983). Elimination of long-term potentiation in the hippocampus by phencyclidine and ketamine. Brain Research, 379, 159-164.

TANG, A. H., \& Ho, P. M. (1988). Both competitive and non-competitive antagonists of $\mathrm{N}$-methyl-D-aspartic acid disrupt brightness discrimination in rats. European Journal of Pharmacology, 151, 143-146.

WhISHAW, I. Q., \& KolB, B. (1984). Decortication abolishes place but not cue learning in rats. Behavioral Brain Research, 11, 123-134.

(Manuscript received October 27, 1988; revision accepted for publication February 15, 1989.) 